\title{
CONF-970617--2 SANA97-0435C
}

W.R. Wawersik ${ }^{1}$, L.W. Carlson ${ }^{1}$, D.J. Holcomb ${ }^{1}$, and R.J. Williams ${ }^{2}$

${ }^{1}$ Geomechanics Department, Sandia National Laboratories, Albuquerque, NM 87185-0751, USA

${ }^{2}$ Structural Behavior Engineering Laboratories, Inc.

Phoenix, AZ 85063, USA

\section{ABSTRACT}

Sandia is a multiprogram laboratory

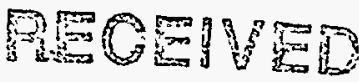
MAP 11 1 operated by Sandia Corporation, a Lockheed Martin Company. for the United States Department of Energy under contract DE-AC04-94AL85000.

Two new and related true-triaxial apparatus are described that make use of conventional triaxial pressure vessels in combination with specially configured, high-pressure hydraulic jacks inside these vessels. The development combines advantages not found in existing facilities, including a compact design, pore-pressure and flow-through capabilities, the ability to attain high principal stresses and principal stress differences, direct access to parts of the sample, and provisions to go to relatively large deformations without developing serious stress field inhomogeneities.

\section{KEY WORDS}

Rock mechanics testing, true-triaxial testing, multiaxial testing, constitutive descriptions.

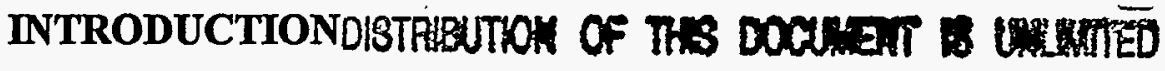 $\ln$

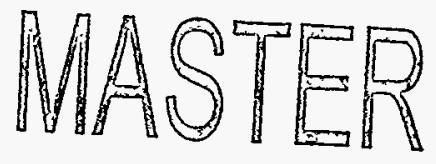

The development of numerical methods during the past thirty years has made it possible to analyze geometrically complex geological and geotechnical problems taking into account the structurally most important characteristics of geomaterials: pressure dependence; non-linear response; volume changes (dilatancy and compaction); stress(microcrack)-induced anisotropy; transition from brittle to ductile, nearly iso-volumetric behavior; strain softening; and difference in compressive and tensile strength. Surprisingly and with notable exceptions (e.g., Lade [1], Desai and Salami [2]), experimental efforts in rock mechanics have not kept up with these developments in that most studies concerning deformation mechanisms and constitutive modeling have been and continue to be based only on data from axisymmetric experiments.

Classical observations of Mogi [3,4] and Handin et al. [5] first suggested that increases in the intermediate principal stress result in a substantial embrittlement coupled with at least some increase in ultimate strength. Several recent and more complete studies have demonstrated that the common generalization of axisymmetric rock properties measurements based only on the mean stress $\left(I_{1} / 3\right)$ and second deviatoric stress invariant $\left(J_{2}\right)$ may be oversimplified [1-11]. Figure 1 shows Desai's and Salami's $\Pi$-plane representation of the ultimate yield (strength) surfaces for rock as a function of mean stress [2]. The shapes of these surfaces, their evolution with pressure and the material parameters marked in Figure 1 were determined in true triaxial compression measurements on concrete and rocks with detailed verifications completed on soapstone. Similar, less extensive results in the literature indicate the measurements of Desai and Salami are typical. Clearly, the triangular yield surfaces observed at low mean stress differ markedly from the circular surface predicted by the von-Mises $\left(J_{2}\right)$ yield criterion. Because of such differences, failure analyses based on axisymmetric data may be misleading when applied to geomechanical problems. For example, stability predictions for deviated boreholes may misjudge wellbore stability. Potentially erroneous stability forecasts may be exacerbated by an embrittlement $[3,4]$ with increases in the intermediate principal stress. Another 


\section{DISCLAIMER}

This report was prepared as an account of work sponsored by an agency of the United States Government. Neither the United States Government nor any agency thereof, nor any of their employees, make any warranty, express or implied, or assumes any legal liability or responsibility for the accuracy, completeness, or usefulness of any information, apparatus, product, or process disclosed, or represents that its use would not infringe privately owned rights. Reference herein to any specific commercial product, process, or service by trade name, trademark, manufacturer, or otherwise does not necessarily constitute or imply its endorsement, recommendation, or favoring by the United States Government or any agency thereof. The views and opinions of authors expressed herein do not necessarily state or reflect those of the United States Government or any agency thereof. 


\section{DISCLAMMER}

Portions of this document may be illegible in electronic image products. Images are produced from the best available original document. 
example of the importance of characterizing behavior under true 3D concerns the constitutive description of rock salt derived from axisymmetric data and attendant model generalizations involving a power law with stress exponent $n=5$. In that case, in situ measurements around an isolated drift in rock salt and model predictions were brought into closer agreement by changing from a von-Mises $\left(\mathrm{J}_{2}\right)$ to a maximum shear stress (Tresca) flow criterion [12]. A third important example refers to the predictions of shear strain localization (faulting) by Rudnicki and Rice [13]. Rudnicki and Rice showed that faulting may result from an instability in constitutive behavior whose occurrence is critically dependent on the three-dimensional state of stress. Specifically, Rudnicki and Rice predicted the onset of faulting after rock has exceeded its peak load-bearing ability in axisymmetric compression but pre-peak, during strain hardening, under some general loading conditions including plane strain loading. The latter prediction can neither be tested nor observed independently in axisymmetric experiments.

\section{EXISTING EXPERIMENTAL FACILITIES}

A recognition of the need for true triaxial measurements has motivated several design efforts generally relying on multiaxial piston, flat-jack, or fluid-bag loading of cubical samples. Three sets of mutually orthogonal actuators probably were used first and most frequently because they allowed large loads and stresses to be generated [14-16]. Substantial improvements to such systems consisted of electrohydraulic servo controls and of brush platens to reduce end-friction [7]. End-effects and alignment difficulties of multipiston systems were also mitigated by the use of flat-jacks inside pressure vessels in lieu of large orthogonally aligned hydraulic actuators [15]. Flat-jacks had the important advantage that they could be installed in conventional triaxial pressure vessels and therefore did not require large expenditures for equipment development. Unfortunately, the pressure limitations of flat jacks restricted the use of these devices to small values of the least and intermediate compressive principal stresses.

A very imaginative experimental development for the true triaxial characterization of soils is due to Ko and Scott [6]. Taking advantage of the low stress requirements in most soil mechanics applications, Ko and Scott replaced rigid, orthogonal multipiston arrangements with pressurized fluid bags coupled with an ingenious mechanical system for servo-control at a time when electro-hydraulic controls still were in the evolutionary stages. Ko and Scott's design resulted in well-defined boundary conditions, virtually eliminated alignment problems, and permitted direct end-to-end sample displacements to be made for the first time. Direct displacement measurements were achieved by means of proximeter gages that could "see through" Ko and Scott's thin pressurized fluid bags.

Ko and Scott's true-triaxial soil testing device was so successful that it spawned scale-ups in pressure capacities for soft and hard rock testing [11,18-21]. Latex fluid bags were replaced by containment devices of stronger but also stiffer materials in order to reach higher absolute pressures and to increase the difference in the pressures in adjoining fluid "bags" before the bags would rupture. The latest adaptations of these machines combine compression and tension loading [11,19]. Tension is generated by the substitution of one set of pressurized fluid bags by tensile loading fixtures that are supported by an external load frame. If the maximum applied principal compressive stresses can be held to under approximately $100 \mathrm{MPa}$ and if no instrumentation needs to be attached to the rock, then the true-triaxial devices that involve fluid-bag loading probably remain the most elegant and reliable of all existing true-triaxial apparatus.

Different approaches to true-triaxial systems were combined by Mogi [4] in order to subject strong rocks to high absolute and differential principal stresses. Mogi first pressurized small, very accurately machined rock samples hydrostatically inside a pressure vessel that had previously been used for standard axisymmetric rock testing. He then added a biaxial state of compression. Biaxial loading was performed by means of the movable axial loading piston of the apparatus and by means of a set of opposing lateral pistons that passed through the cylindrical wall of the pressure vessel shell and reacted against a separate external load frame. Mogi immediately gained the ability to instrument his samples on the two faces that were not covered by 
pistons. However, it is not obvious to the present authors how Mogi's design might be adapted to larger samples and how considerable assembly and alignment difficulties might be reduced.

Recent thin and thick-walled pressurized cylinder tests with and without torsion provided important novel data on fine-grained rocks and made it possible to rotate the principal stress axes during testing [22-23]. Pressurized thick-walled cylinder tests proved useful in verification studies of code-based geotechnical design procedures in which stress gradients were not only acceptable but a deliberate part of the test [24].

An intriguing very recent concept achieves true triaxial stress conditions on cylindrical samples by combining conventional axisymmetric loading with "the application of an azimuthally varying radial pressure to the curved surfaces" of the specimen [25]. The latter is accomplished by "pressurizing individual tubes which are aligned with the long axis of the specimen and are trapped between the curved surfaces of the specimen and an outer pressure vessel." This so-called "Smart" design in Main et al. [24] appears to offer opportunities to study not only three-dimensional stress states but the effects of principal stress rotations previously attainable only in pressurized torsion experiments.

\section{SANDIA TRUE TRIAXIAL FACILITIES}

\section{System Descriptions}

Two new but similar true-triaxial testing facilities at Sandia National Laboratories represent compromises that rely on a combination of hydrostatic and biaxial piston loading of rectangular parallelepipeds inside conventional pressure vessels (Figures 2 and 3). The Sandia design resembles Mogi's approach but differs in several important ways. Above all, pressure normal to the long axis of the pressure vessel is generated by means of a set of compact, servo-controlled hydraulic jacks completely contained by and reacting against the walls of the pressure vessel (Figures 2 and 3). The hydraulically loaded main pistons of these devices are not circular but oval and extend beyond the length of the sample in order to maximize loading capacity (Figure 4). The effects of bending moments are eliminated by the placement of another set of pistons and rubber sheets between the main pistons and the two faces of the rock sample (Figures 2 and 4).

The first of the new Sandia true-triaxial systems made use of an existing $400 \mathrm{MPa}$ pressure vessel with a fixed axial loading piston at the bottom and only one movable piston at the top as is the normal practice in triaxial rock mechanics laboratory testing. The $12.7-\mathrm{cm}$ bore of this vessel determined the maximum sample size of $5.7 \times 5.7 \times 2.5 \mathrm{~cm}$. This left just enough space for the placement of instrumentation (strain gages, proximeters, and LVDTs) on and across the pair of exposed sample faces. To facilitate test assembly, the sample, endcaps, lateral loading jacks, and instrumentation were all placed onto the bottom piston and end closure (reaction) plate (Figures 2 and 3). Once this assembly was complete and all electrical connections made to feedthroughs around the bottom loading piston, the pressure vessel shell was lowered from above and the top pressure vessel closure installed and secured.

The second and complementary Sandia true-triaxial design is shown in the assembly drawing in Figure 2. The inside diameter of the pressure vessel in this version was increased to $17.8 \mathrm{~cm}$ in order to accommodate samples up to $7.6 \times 7.6 \times 17.8 \mathrm{~cm}$ with special provisions for $10.2 \times 10.2 \times 20.3-\mathrm{cm}$ samples. The difference in sample shape and size between the first and second Sandia true triaxial facilities is shown in Figure 3.

A scale-up of our first true-triaxial machine was undertaken to (i) characterize larger, relatively heterogeneous samples, (ii) add pore pressure and fluid-flow capabilities, and (iii) test soft rocks undergoing axial strains up to at least $15 \%$. Pore pressure and fluid-transport capabilities are provided by several fluid ports through the axial loading pistons and in the base plate of the pressure vessel (Figure 2). To accomplish the third goal without unacceptable lateral stress variations, the sample center and the center of the compact lateral loading jacks have to remain coincident as the sample is deformed. This requirement was met by 
allowing the pressure vessel in Figure 2 to ride on a circular, inflatable seal in such a way that the seal height during deviatoric loading (i.e., the relative motion between the bottom loading piston and the pressure vessel) always changes by half of the axial sample shortening. This scheme is accomplished by regulating the seal pressure through an air-driven servo-control system, and it works because the friction between the soft (protective) shoes of the lateral loading jacks (Figures 2 and 3 ) and the interior of the pressure vessel is higher than the friction across the lubricated contact area between the jacks and the rock sample.

Even for the largest sample sizes, the 17.8-cm bore of the pressure vessel has ample room for instrumentation that is connected to 24 electrical feedthroughs around the bottom closure (Figure 3). If necessary, additional electrical connections can be completed using feedthroughs in the top closure as well. High frequency, low amplitude acoustic emission signals are transmitted through compact coaxial feedthroughs.

The design outlined here and shown in Figures 2 through 4 appears to have several advantages over other known methods of three-dimensional rock loading: (1) Relatively large absolute principal stresses and principal stress differences can be achieved. For example, the largest difference between the intermediate and smallest applied principal compressive stresses, is $\left(\sigma_{2}-\sigma_{3}\right)=150 \mathrm{MPa}$ at $\sigma_{3}=100 \mathrm{MPa}$ for sample dimensions of $6.4 \times 6.4 \times 15.2 \mathrm{~cm}$. Higher values are possible as the sample size is reduced. (2) Considerable freedom of motion of the loading pistons of the compact horizontal hydraulic jacks ensures good alignment between the loading fixtures and the rock sample. (3) One pair of sample faces is pressurized by means of hydraulic fluid and remains accessible for direct observation and placement of instrumentation. (4) Multi-directional loading can be carried out at elevated pore pressure. (5) The system is capable of combining true three-dimensional mechanical loading tests with real-time flow (permeability) measurements in the axial and eventually in two orthogonal directions. (6) The design of both Sandia true-triaxial testing systems is compact and probably less costly than other apparatus with similar load and pressure capacities. The total system costs were curtailed by combining the designs of the Sandia compact hydraulic jacks with the basic design of standard triaxial pressure vessels. In this case, it was advantageous to rely on and apply the necessary modifications to pressure vessels by Structural Behavior Engineering Laboratory, Inc. (SBEL).

\section{Instrumentation and Test Implementation}

Figure 3 shows some of the instrumentation that is used to measure rock deformations or strains. In many cases, strain gages are mounted directly onto the rock surfaces or on thin copper substrates in highly porous rocks (small sample in Figure 3). Axial sample strains are derived from strain gage measurements or from a pair of LVDTs that are attached to the end caps approximately $0.6 \mathrm{~cm}$ away from the rock-end-cap interfaces. Strain-gaged clip gages also yield the displacement in one lateral direction parallel to the action of the compact hydraulic jacks (Figure 3). These gages are reliable as soon as the jacks have become fully seated, but improvements in the gage placement are needed to measure displacements under hydrostatic loading and at small differential stresses.

Displacement measurements normal to the exposed faces (Figure 2) are carried out in two ways. For small samples in the earlier Sandia true triaxial apparatus, a pair of noncontacting proximeters are used that track the displacements of bare copper targets (small sample in Figure 3). LVDT displacement transducers on Invar mounts are used in the larger system (larger sample in Figure 3). The Invar mounts, in turn, rest on top of the compact hydraulic jacks or on the adjustable base as shown in Figure 2. Note that the position of the sample center relative to the lateral loading jacks does not change in what we refer to as the "floating vessel" mode of operation. Changes in this same relative distance are small if the total axial sample displacements are small for hard rocks. Therefore, in such instances the inflatable seals of the system (Figure 2) may not be activated, and instead, the pressure vessel sits on blocks in a fixed position like any conventional triaxial pressure vessel with only one movable axial loading piston.

The successful implementation of Sandia's approach to true triaxial rock mechanics testing requires suitable techniques for sample jacketing and strain/deformation measurements, especially for soft rocks. To date, the 
two sample faces to be loaded by means of pistons are coated with a very thin film of lubricant [26]. The sample is then placed between metal end-caps, and copper shims are folded around the pair of faces that will be contacted by the nested pistons of the compact hydraulic jacks in Figure 2. At that point, the remaining two sample faces and all rock-metal seams are coated with polyurethane. A fully jacketed small rock sample is shown in Figure 3. To minimize end-effects, the end-caps between soft rocks and the axial loading pistons are made of aluminum. Additionally, $0.08 \mathrm{~mm}$ thick etched Teflon sheets are bonded to the lateral loading pistons to reduce the friction coefficient between these pistons and the copper shims around two of the sample faces.

The availability of modern servo-controls makes it possible to characterize materials under virtually any conceivable stress path. In practice, however, truly three-dimensional loading is easier if one principal stress is held constant and the other two are changed proportionally. The latter approach is generally used here in order to determine the shapes of damage, yield, failure, and compaction surfaces in the deviatoric plane in principal stress space, i.e., in the plane (or planes) normal to the hydrostatic axis $\sigma_{1}=\sigma_{2}=\sigma_{3}$. For each value of mean stress, $I_{1} / 3$, the shape of these surfaces is determined by a radius vector whose magnitude is proportional to the square-root of the second deviatoric stress invariant at failure (ultimate stress), $\sqrt{J_{2}^{u}}$, and which is oriented at an angle $\theta$ (Lode angle) with respect to the projection of the $\sigma_{1}$-axis onto the deviatoric plane. Confining pressures, $\sigma_{3}$, and proportional stress paths preferably are chosen to yield values $\theta \approx 0^{\circ}, 15^{\circ}$, $30^{\circ}, 45^{\circ}$, and $60^{\circ}$ where

$$
\theta=\tan ^{-1} \frac{\sqrt{3}\left(\sigma_{2}-\sigma_{3}\right)}{2 \sigma_{1}-\sigma_{2}-\sigma_{3}}
$$

The Lode angles are obtained by a combination of axisymmetric triaxial compression and extension tests, pure shear measurements at constant $\sigma_{2}$, and true triaxial, proportional loading experiments at constant $\sigma_{2}$ or $\sigma_{3}$.

TABLE 1

Failure (ultimate stress) data for Gosford sandstone as a function of deviatoric stress path and mean stress.

\begin{tabular}{|l||c|c|c|}
\hline $\begin{array}{c}\text { Deviatoric Stress } \\
\text { Path }\end{array}$ & $\begin{array}{c}\text { (Lode) } \\
\text { Angle } \\
\theta^{\circ}\end{array}$ & $\begin{array}{c}\text { Mean Stress } \\
\mathrm{I}_{1} / 3 \\
\mathrm{Mpa}\end{array}$ & $\begin{array}{c}\text { Deviatoric Stress } \\
\sqrt{J_{2}^{u}} \\
\mathrm{Mpa}\end{array}$ \\
\hline \hline$\sigma_{2}=\sigma_{3} ; \mathrm{I}_{1} / 3=$ const. & 0 & 76.9 & 78.0 \\
\hline$\sigma_{3}=$ const; proportional & 21.0 & 77.0 & 63.4 \\
\hline$\sigma_{2}=$ const; $\mathrm{I}_{1} / 3 \approx$ const.; pure shear & 31.3 & 77.7 & 65.6 \\
\hline$\sigma_{3}=$ const., plane strain & 45.8 & 76.9 & 58.8 \\
\hline$\sigma_{2}=\sigma_{3}=$ const.; conventional triax. & 0 & 78.8 & 80.6 \\
\hline$\sigma_{3}=$ const.; proportional & 21.0 & 74.2 & 61.2 \\
\hline
\end{tabular}

Table 1 and Figure 5 show two examples of how the present true triaxial testing is being implemented. Table 1 contains a collection of measurements that were intended to determine the shape of the failure (ultimate stress) surface for Gosford sandstone in the deviatoric plane at constant mean stress, $I_{1} / 3 \approx 77 \mathrm{MPa}$. Considering the top four deviatoric stress values, $\sqrt{J_{2}^{u}}$, it appears that the shape of the failure surface at this pressure still is distinctly non-circular. Note also, however, a pronounced influence of the mean stress. As a result, conclusive direct observations concerning failure require that the mean stress is tightly controlled or that the number of measurements (preferably at the same Lode angle) is large enough to conduct credible data interpolations. Two different stress paths in axisymmetric triaxial experiments $\left(\sigma_{2}=\sigma_{3}\right.$; Table 1$)$ were performed specifically to evaluate any distinct effect of the mean stress history. 
The measurements in Figure 5 were made on Castlegate sandstone which is a commonly used analogue of clastic reservoir rocks with about $25 \%$ porosity. Fig. 5(a) demonstrates a typical experimental history of the applied principal stresses from hydrostatic through proportional loading at $\sigma_{3}=p=18.6 \mathrm{MPa}$ and $\left(\sigma_{1}-p\right) /\left(\sigma_{2^{-}}\right.$ p) $=1.41$. The three-dimensional stress-strain records in Fig. 5(b) were measured by means of LVDTs, strain gaged clip-gages, and proximeters parallel to the $\sigma_{1}, \sigma_{2}$, and $\sigma_{3}$ directions, respectively. Data of this type are currently being used to determine the evolution of the Rudnicki-Rice constitutive parameters [22,23,28-32] in order to test the Rudnicki-Rice bifurcation theory $[13,32]$ for strain localization.

\section{SUMMARY AND CONCLUSIONS}

Previous authors stated, and this account reiterates, that mechanical testing under general stress states and along arbitrary stress paths is important for a complete understanding of the constitutive behavior of rocks and the response of complex geologic systems. Mechanical testing under true three-dimensional stress states is also needed to evaluate hypotheses and develop theories for phenomena such as shear-strain localization underlying geologic faulting. To accomplish this, two new and related true-triaxial apparatus were described that make use of conventional triaxial pressure vessels and combine advantages not found in existing facilities, including a compact design, pore-pressure and flow-through capabilities, the ability to attain high principal stresses and principal stress differences, direct access to parts of the sample, and provisions to go to relatively large deformations without developing serious stress field inhomogeneities.

\section{ACKNOWLEDGMENTS}

This work was supported by the United States Department of Energy under Contract DE-AC04-94AL85000. Sandia is a multiprogram laboratory operated by Sandia Corporation, a Lockheed Martin Company, for the United States Department of Energy. Primary support was provided by the US Department of Energy (DOE), Office of Basic Energy Sciences and Office of Fossil Energy, Bartlesville Energy Technology Center. Additional support was granted by DOE, Yucca Mountain Characterization Project. The authors thank S.R. Brown, R.D. Hardy, W.A. Olsson, and D.S. Preece for many helpful discussions. D.S. Preece conducted several finite element design analyses.

\section{REFERENCES}

1. Lade, P.V. (1971). Three-parameter failure criterion for concrete. J. Engrg. Mech. Div., Am. Soc. Civ. Engrs., 97:6, 935-950.

2. Desai, C.S., and Salami, M.R. (1987). A constitutive model and associated testing for soft rock. Int. J. Rock Mech. Min. Sci. \& Geomech. Abstr., 24:4, 299- 3077.

3. Mogi, K. (1967). Effects of the intermediate principal stress on rock failure. J. Geophys. Res., 72, 20, 5117-5131.

4. Mogi, K. (1971). Fracture and flow of rocks. Tectonophysics, 13, 541-568.

5. Handin, J., Heard, H.C., and Magourik, J.N. (1967). Effects of the intermediate principal stress on the failure of limestone, dolomite, and glass at different temperatures and strain rates. J. Geophys. Res., 72,2 611-640.

6. Ko, H.-Y. and Scott, R.F. (1967). A new soil testing apparatus, Geotechnique, 17, 40-57 (1967).

7. Hilsdorf, H. (1965). Versuchs-technische Probleme beim Studium der zweiachsigen Festigkeit des Betons. PhD Thesis, Techn. Univ. Munich, Germany.

8. Costin, L.S. (1983). A microcrack damage model for the deformation and failure of brittle rock. $J$. Geophysc. Res., 88, 9485-9492.

9. Costin, L.S., (1985). Damage mechanics in the post-failure regime. Mech. Mat., 4, 149-160.

10. Schreyer, H. (1989). Smooth limit surfaces for metals, concrete, and geotechnical materials. J. Engr. Mech., 115:9. 
11. Amadei, B; and M.J. Robison, (1986). Strength of rock in multiaxial loading conditions. Proc. 27th U.S. Symp. Rock Mech., University of Alabama, 47-55.

12. Munson, D.E., Fossum, A.F., and Senseny, P.E. (1989). Advances in resolution of discrepancies between predicted and measured in situ WIPP room. Report SAND88-2948, Sandia National Laboratories, Albuquerque, NM.

13. Rudnicki, J.W., and Rice, J.R., (1975). Conditions for the localization of deformation in pressuresensitive dilatant materials. J. Mech. Phys. Solids, 23, 371-394.

14. Kern, H., and Karl, F. (1969). Eine dreiaxial wirkended Gesteinspresse mit Heizvorrichtung. Bergbauwissenschaften, 16, 90-92.

15. Hunsche, U. (1992). True triaxial failure tests on cubic rock salt samples - experimental methods and results. Proc. IUTAM Symp. on Finite Inelastic Deformations - Theory and Applications, Hannover, Springer Verlag, 525-538

16. Kern, H., Liu, B., and Popp, T. (1997). Relationship between anisotropy of P- and S-wave velocities and anisotropy of attenuation in serpentinite and amphibolite. J. Geophys. Res., 102:B2, 3051-3056.

17. Hojem, J.P.M., and Cook, N.G.W. (1968). The design and construction of a triaxial and polyaxial cell for testing rock specimens. S. Afr. Mech. Engr., 18, 57-61.

18. Atkinson, R.H. and Ko, H.Y. (1973). A fluid-cushion multiaxial cell for testing cubical rock specimens. In. J. Rock Mech. Min. Sci. \& Geomech. Abstr., 10,351-361.

19. Meier, R.W., Ko, H.Y., and Sture, S. (1974). Mechanical characterization of anisotropic materials. J. Composite Materials, 8, 178-190.

20. Desai, C.S., Janardahanam, R, and Sture, S. (1982), High capacity multiaxial testing device. Geotechnical Testing Journal, 5:1, 26-33.

21. Michelis, P. (1985). A true triaxial cell for low and high pressure experiments. Int. J. Rock Mech. Min. Sci. \& Geomech. Abstr., 22:3, 183-188..

22. Olsson, W.A., (1992). The formation of a yield-surface vertex in rock. Proc. 33rd. U.S. Symp. Rock Mech., Santa Fe, Balkema, 701-705.

23. Olsson, W.A., (1995). Development of anisotropy in incremental shear moduli for rock undergoing inelastic deformation. Mech. Mat., 21, 231-234.

24. Morgan, H.S., and Wawersik, W.R., (1991). The use of thick-walled hollow cylinder creep tests for evaluating flow criteria for rock salt. Proc. 7th Int. Congr. Rock Mech., Aachen, Balkema, 303-310 .

25. Main, I.G., Smart, B.G.D. , Shimmield, G.B., Elphick, S.C., Crawford, B.R., and Ngwenya, B.T., (1994). The effects of combined changes in pore fluid chemistry and stress state on permeability in reservoir rocks: preliminary results from analogue materials. North Sea Oil and Gas Reservoirs - III, Chptr. 25, Norwegian Institute of Technology (NTH), 357-370.

26. Labuz, J.F., and Vridwell, J.M. (1193). Reducing frictional constraint in compression testing through lubrication. In. J. RockMech. Min. Sci. \& Geomech. Abstr., 30:4,451-455.

27. Wawersik, W.R, Rudnicki , J.W.,. Olsson, W.A., Holcomb, D.J., and Chau, K.T. (1990). Localization of deformation in brittle rock: theoretical and laboratory investigations. Micromechanics of Failure of Quasi-Brittle Materials, Elsevier, 15-124.

28. Holcomb, D.J. (1991). Evolution of damage surfaces and plastic potential in a limestone. Proc. Soc. Experim. Mech. Spring Conf., Soc. Experim. Mech., 818-825.

29. Holcomb, D.J., (1992). Localization studies under triaxial conditions. Proc. 33rd. U.S. Symp. Rock Mech., Santa Fe, Balkema, 661-670.

30. Rudnicki, J.R., and Chau, K.-T., (1996). Multiaxial response of microcrack constitutive model for brittle rock. Proc. 2nd North American Rock Mech. Symp., A.A. Balkema, Rotterndam, 1707-1720.

31. Rudnicki, J.R., Wawersik, W.R., and Holcomb, D.J., (1997). Microcrack damage model for brittle rock. Proc. Symp. Inelasticity \& Damage in Solids Subject to Microstructural Change. Memorial Univ. of Newfoundland, Newfourndland, Canada (in press).

32. Rudnicki, J.R., (1984). A class of elastic-plastic constitutive laws for brittle rock. J. Rheology. 26:6, 759-778. 


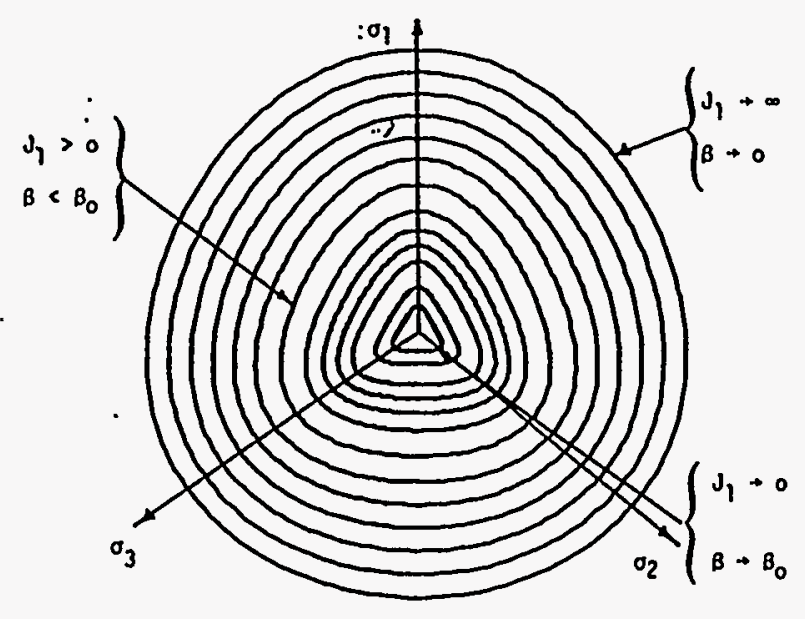

Figure 1: Predicted variation of ultimate yield surface of soapstone with mean stress. After Desai and Salami [2]. $J_{1}$ denotes mean stress $\left(I_{1} / 3\right.$ in this paper). $\beta$ and $\beta_{0}$ are model parameters.

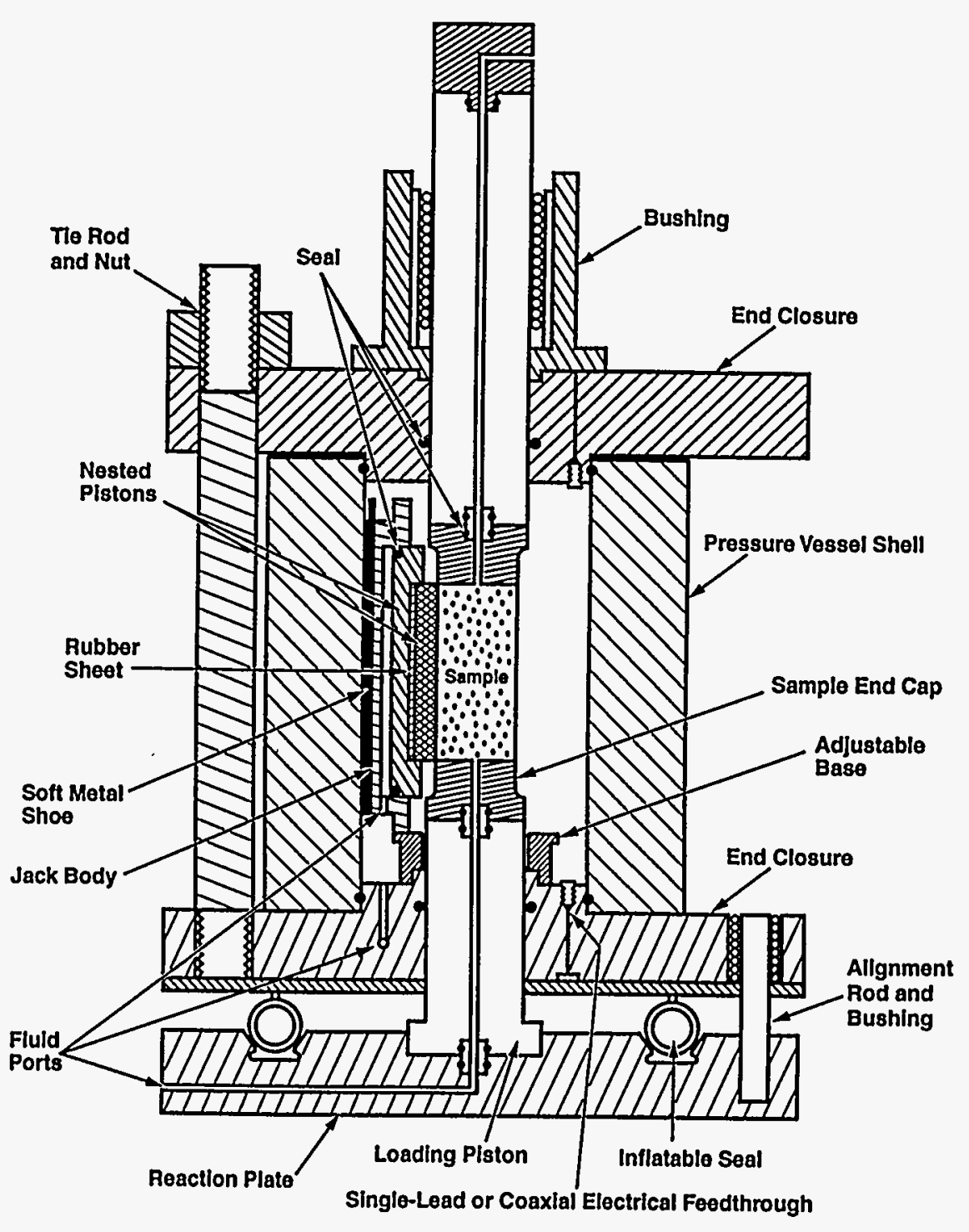

Figure 2: Schematic of Sandia true-triaxial testing system with "floating" pressure vessel shell. Note: only one of two opposing compact hydraulic jacks is shown. Inflatable seal may be replaced by rigid spacers to fix pressure vessel position relative to lower (axial) loading piston. Drawing not to scale. 


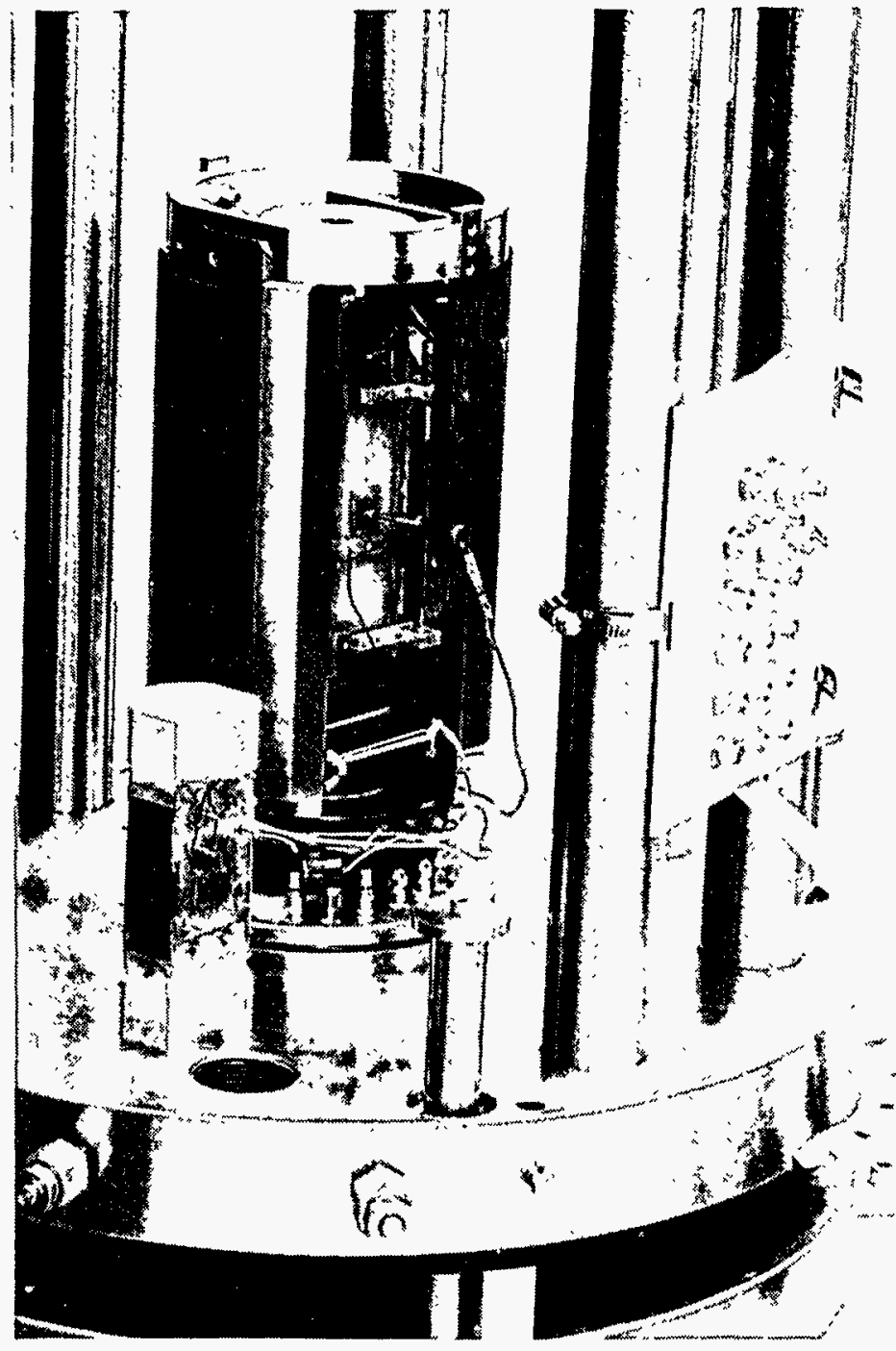

Figure 3: Photograph of $5.1 \times 5.1 \times 12.7-\mathrm{cm}$ sample, compact hydraulic jack assembly, and instrumentation (LVDTs and clip gage) of second (larger) true-triaxial testing system. Pressure vessel shell $(17.8 \mathrm{~cm} ; 38.1 \mathrm{~cm} \mathrm{O.D.)}$ fits inside ring of vertical tie rods. Note lower guide rod at front bottom of figure. For comparison, picture shows small $5.7 \times 5.7 \times 2.5-\mathrm{cm}$ sample between aluminum end-caps. Small-sample assembly includes location pins for axial LVDTs, strain gages, copper target, and piezoelectric transducers for acoustic emissions monitoring.

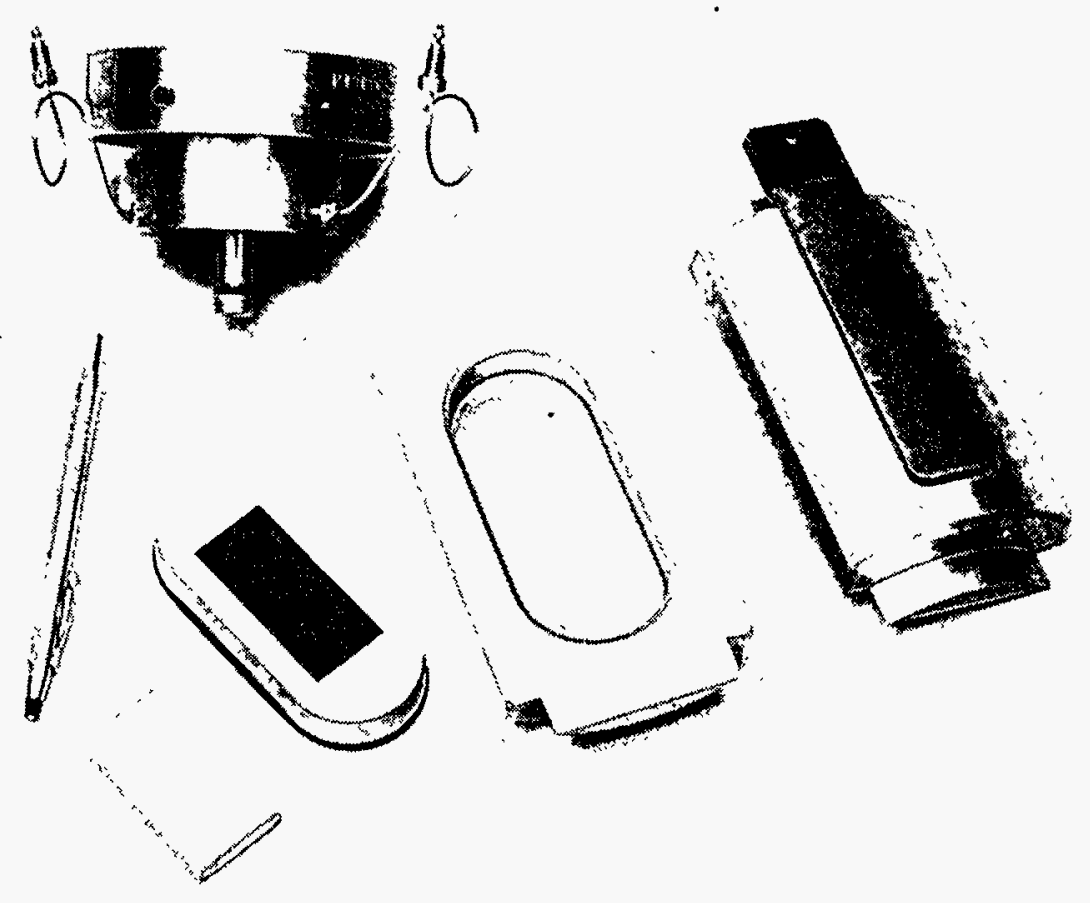

Figure 4: Components and assembly of compact hydraulic jacks for true triaxial testing of $5.7 \times 5.7 \times 2.5-\mathrm{cm}$ samples. Parts to right of ball-point pen: small and larger pistons of nested piston set (see Figure 2 and text), jack housing, and fully assembled jack with soft shoe on back as shown on larger jacks in Figure 3. Above ball-point pen: base for sample assembly and hydraulic jacks. Fluid port at bottom of base feeds pressure lines to jacks in first (small) Sandia systems but provides pore pressure in samples inside second (larger) Sandia apparatus. 


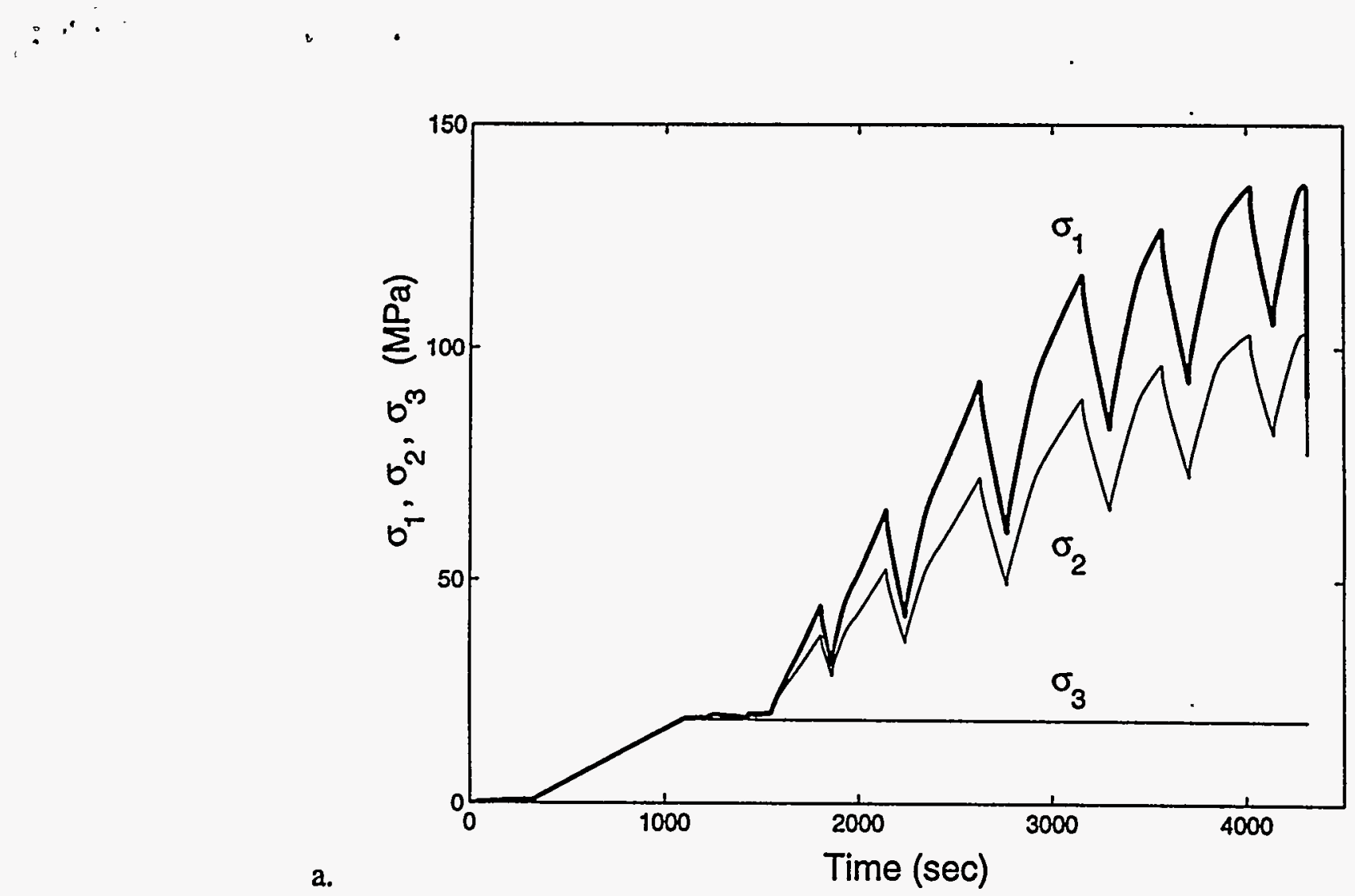

a.

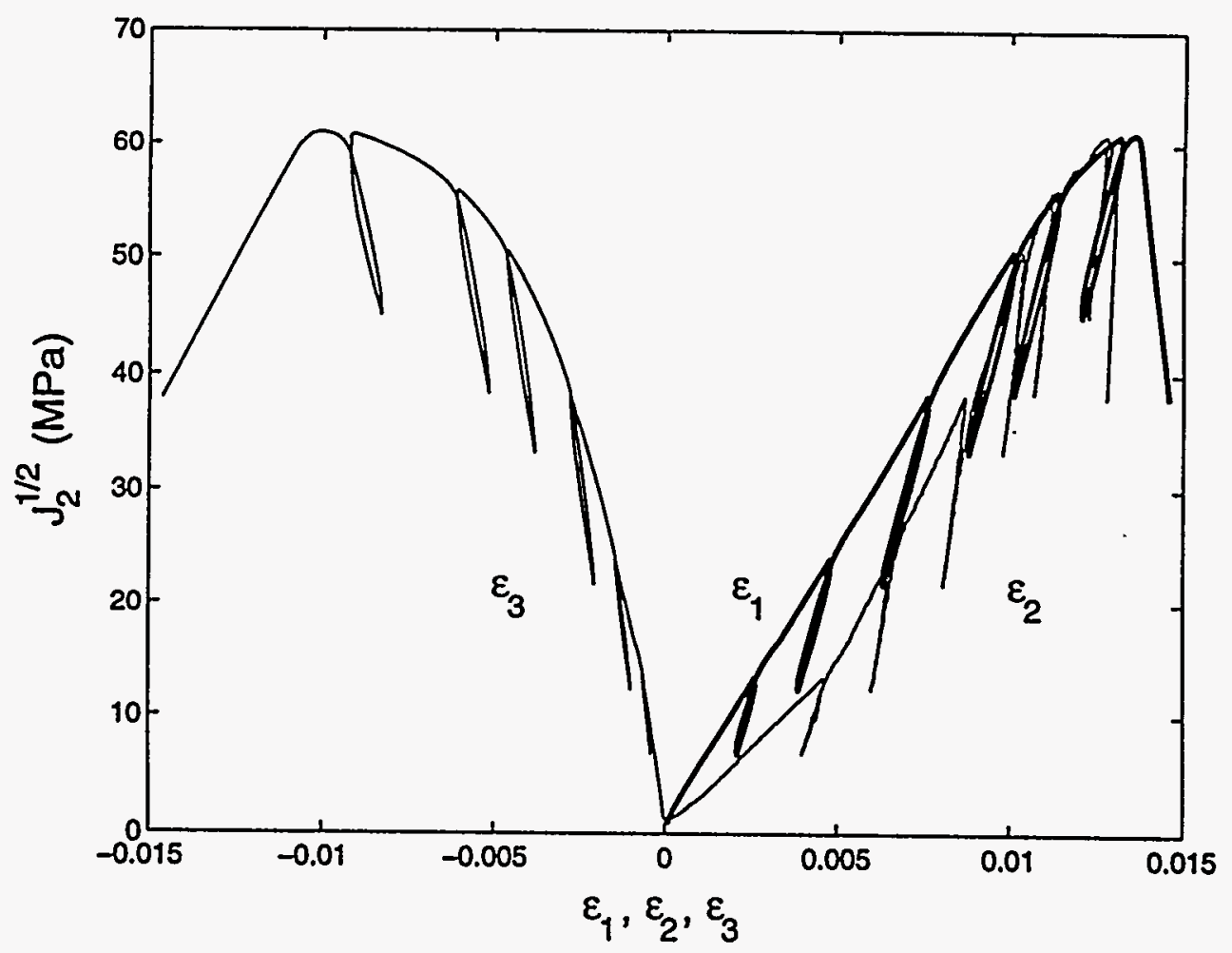

Figure 5: Experimental data for (a) Gosford sandstone and (b) Castlegate sandstone subjected to proportional loading, ( $\sigma_{3}=$ constant) at fixed confining pressures. Note: $\sigma_{1} \geq \sigma_{2} \geq \sigma_{3} \geq 0$ and

$$
\sqrt{J_{2}}=\left[\frac{1}{6}\left(\left(\sigma_{1}-\sigma_{2}\right)^{2}+\left(\sigma_{2}-\sigma_{3}\right)^{2}+\left(\sigma_{3}-\sigma_{1}\right)^{2}\right)\right]^{\frac{1}{2}}
$$

